\title{
ILÍADA LATINA: A ADAPTAÇÃO RESUMIDA DA ILÍADA DE HOMERO
} ILIAS LATINA: THE RESUMED ADAPTATION OF HOMER 'S ILIAD

\author{
Priscilla Adriane Ferreira Almeida ${ }^{1}$
}

Resumo: a Ilíada latina é um resumo da Ilíada, da época de Nero. Já no século I a. C., o mito troiano passou a ser cada vez mais conhecido pelo povo através de resumos e adaptações da Ilíada, já que o poema grego era apenas conhecido pela elite. A Ilíada latina foi uma das adaptações mais populares dessa época, e a única desse período que nos chegou bem preservada. Pretendemos neste artigo focar em certos aspectos do enredo da Ilíada latina $e$ fazer um estudo comparativo com trechos da Ilíada. Com esse estudo, perceberemos como o povo romano conhecia a história da guerra de Troia através dessa adaptação.

Palavras-chave: Ilíada, Ilíada latina, poesia épica, literatura latina

Abstract: the Ilias latina is a resume of the Iliad, from Neronian times. In the first century B.C, the Trojan myth gradually became known by the people through resumes and adaptations of the Iliad, since the Greek poem was known only by the aristocracy. The Ilias latina was one of the most popular of these adaptations, and the only one of this period that is well preserved. We intend in this article to focus on some plot's aspects of the Ilias latina and make a comparative analysis with parts of the Iliad. With this essay, we'll perceive how the Roman people knew the Troy war history through that adaptation.

Keywords: Ilias, Ilias latina, epic poetry, latin literature

\section{Introdução}

Pretendemos neste artigo esclarecer um pouco mais sobre a Ilíada lati$n a$, essa desconhecida obra da época de Nero, a qual mais tarde acabou se tornando referência para conhecer o ciclo troiano durante o fim da Antiguidade. Também faremos um estudo comparativo entre a Ilíada latina e a Ilíada focando em certos aspectos do enredo dessas obras.

1 Doutoranda do Programa de Pós Graduação da Faculdade de Letras da Universidade Federal de Minas Gerais. 
O poema Ilíada latina (Ilias latina) é um resumo em latim da Ilíada de Homero, com 1070 versos em hexâmetros datílicos - por oposição aos 16.000 versos do texto grego - e apresenta uma linguagem despretensiosa e clara. Já no século I a. C., as lendas relacionadas ao mito troiano passavam a ser cada vez menos conhecidas através da Ilíada, já que o grego era apenas aprendido pela elite romana.

Assim, encontrando-se os livros de Homero de certo modo inacessíveis, as versões, epítomes e resumos eram muito comuns, e a Ilíada latina correspondeu a uma das adaptações mais antigas e populares. Já havia em Roma, desde o século III a. C., a tradução de trechos da Odisseia, feita por Lívio Andronico. Ao fim do período republicano surgem outras traduções da Ilíada, que não alcançaram sucesso. Do século I d. C. também temos traduções desta obra feitas por Átio Labeão, Pérsio, e Políbio, que não nos chegaram. Tem-se ainda notícia da obra perdida de Lucano, Iliacon, da qual restou apenas o título, e entrevê-se, no Satyricon de Petrônio, o poema A queda de Troia. As várias obras sobre a Guerra de Troia do período se justificam pela paixão que o imperador Nero nutria por esses mitos, chegando, inclusive, a compor um poema a seu respeito, chamado Troica, agora perdido (CONTE, 1999, p. 436).

Além disso, a obra fez parte da tradição escolar, junto com Lucano, Virgílio, Estácio, Juvenal e Horácio (Arte poética e epístolas), por sua linguagem despojada e sua brevidade (BUTLER, 2008, p. 159). Justamente por ter sido muito utilizada nas escolas é que foi bem preservada até os dias de hoje: restam trinta manuscritos, sendo os mais antigos dos séculos X e XI.

\section{Da autoria e data de composição da obra}

Desde a Antiguidade a obra permaneceu anônima, embora várias atribuições de autoria tenham sido feitas. Devido aos acrósticos que abrem e fecham o poema (Italicus scripsit), a Ilíada latina foi erroneamente atribuída a Sílio Itálico (autor dos Punica, obra épica a respeito das guerras entre romanos e cartagineses). Essa teoria, por muito tempo defendida pelos estudiosos do tema, foi contestada. Em 1890, o pesquisador H. Schenkl descobriu, em um códice humanístico de Viena, o Vindobonensis Latinus 3509, o nome de Bébio Itálico (Baebius Italicus) na inscrição que encabeça

o poema: "Bebii Italici poetae clarissimi epithome in quatuor viginti libros Homeri Iliados".

2 Do ilustre poeta Bébio Itálico, epítome em vinte e quatro livros da Ilíada de Homero. 
Atualmente, muitos estudiosos como Marco Scaffai, professor da Universidade de Bologna, concordam com essa autoria atribuída a Bébio, que teria sido um político da época de Nero. Podemos encontrar também em Marcial outro fator que contesta a autoria de Sílio. A seu respeito, Marcial afirma:

Depois que, tendo duas vezes seis fasces ${ }^{3}$, governara o longo ano que foi venerável ao mundo livre, ele ofereceu às Musas e a Apolo os anos concluídos e, ao invés do seu foro, frequenta agora o Hélicon.

(MARCIAL, VII, 63, vv. 9 a 12)

Se assim fosse, Sílio teria escrito a Ilíada latina após o período neroniano. Sabemos que, no ano da morte de Nero, Sílio era cônsul, e que só se dedicou à literatura após se retirar da vida pública. A datação da obra, porém, é clara: foi escrita até, no máximo, o fim do reinado de Nero, ou um pouco antes (BUTLER, 2008, p. 183).

Já era conhecida a existência de uma família ou de pelo menos algumas pessoas no século I d. C. relacionadas ao nome de Bébio Itálico, quando foram descobertas em Tlos, cidade da Lícia, algumas epígrafes gregas, em parte fragmentadas, que ornavam um monumento erguido em $85 \mathrm{em}$ honra de Bébio Itálico, que governou aquela região oriental como legatus Augusti. Apesar dessa descoberta, ainda faltava definir a data do poema, e consequentemente havia dificuldade em considerar Bébio o autor da Ilíada latina.

Posteriormente, foi encontrado um fragmento de uma placa marmórea proveniente da antiga Potentia Picena, atualmente a vila italiana Potenza Picena, próxima a Ancona, contendo os Fasti consulares dos anos 86-93 e 113-116. Entre os nomes mencionados no ano 90, aparece P. Baebius Italicus.

Scaffai assim descreve a sua vida:

Pertencente à tribo Oufentina, italiano de nascença, foi questor em Chipre e tribuno da plebe durante Vespasiano, e provavelmente foi um dos tantos adlecti in senatum de família não patrícia; foi depois propretor na Gália Narbonense, legado da legião XIV Gemina em 83 (...), legatus Augusti pro praetore na Lícia-Panfília de 84-5 a 87, e finalmente toca o auge com o consulado

3 Segundo o dicionário de Ernesto Faria, fasces eram feixes de varas de olmo ou bétula ligadas por uma correia, muitas vezes com uma machadinha no meio delas, que os "litores" levavam à frente dos primeiros magistrados como símbolo do poder que lhes cabia de condenar a morte. No poema, Marcial usa esse termo para designar a carreira política de Sílio.

Organon, Porto Alegre, v. 29, n. 56, p. 297-312, jan/jun. 2014. 
em 90. Depois dessa data do personagem perdem-se todos os registros $^{4}$ (SCAFFAI, 1997, p. 18).

Assim, reconstruída brevemente a vida de Bébio Itálico, é possível, através do cursus honorum, basear seu nascimento em 50. Podemos situar sua atividade poética limitada à juventude, dado o forte aspecto escolástico que marca o poema, quando, segundo Scaffai $(1997$, p. 18) os jovens de talento, por volta dos 18-20 anos, estreavam os seus primeiros frutos. Desta maneira, com base na reconstrução biográfica feita por Scaffai, podemos concluir que a composição da Ilíada latina se situa por volta do ano $68 \mathrm{~d}$. C. Outro fator que determina a datação da obra durante o reinado de Nero pode ser visto na descrição do escudo de Aquiles, que diz:

A terra tem florestas e horrendos monstros das feras, os, montes e cidades de altos muros,

nas quais os povos exercem as leis e o velho direito disputando; assenta-se ali o juiz, imparcial para as duas partes, e o processo julga com fronte serena. Em outra parte castas moças ressoam o Peã ${ }^{5}$ apresentam danças suaves e a destra agita os tambores; com o polegar estendido, as delgadas cordas da lira ele percorre e sete compassos modula na flauta pastoril: os sons em ressonância compõem o movimento do mundo ${ }^{6}$. Outros os campos cultivam, sulcam as duras terras os novilhos, o robusto ceifador colhe as espigas maduras e alegra-se com as uvas prensadas o imundo vindimador; os rebanhos comem os prados, pendem nas rochas as cabras. (Ilíada latina, XVIII, v. 875 a 888, tradução nossa)

Podemos perceber o forte caráter de justiça, na figura do juiz imparcial; e de paz, pois os homens calmamente cultivam os campos, e os animais

4 Todas as traduções de citações são nossas. "Appartenente alla tribù Oufentina, italiano di nascita, fu questore a Cipro e tribuno della plebe sotto Vespasiano, e probabilmente fu uno dei tanti adlecti in senatum di famiglia non patrizia; fu poi propretore nella Gallia Narbonense, legato della legio XIV Gemina nell 83 (...), legatus Augusti pro praetore in Licia-Pamfilia dall ' 84-5 all ' 87, per toccare infine l' acme della carriera col consolato del 90. Dopo tale data del personaggio si perde ogni traccia."

5 As castas moças são as Musas, que em seu canto usam o verso métrico chamado peã, utilizado em composições que celebram Apolo; Apolo, deus da poesia, é quem toca a lira no verso 882.

6 A descrição do mundo realizada nessa passagem está de acordo com a doutrina pitagórica da harmonia entre as esferas celestes. 
pastam. Essa exaltação da paz e da justiça difere bastante de Homero. Na descrição das cidades do escudo de Aquiles, ele assim escreve:

E fez duas cidades de homens mortais, cidades belas. Numa havia bodas e celebrações;

(...) mas o povo estava reunido na ágora; pois surgira aí um conflito e dois homens discutiam a indenização por outro, assassinado. Um deles afirmava ter pago tudo, em declarações ao povo; o outro negava-se a aceitar o que fosse. (...) Mas por volta da outra cidade estavam dois exércitos, refulgentes de armas. Duas alternativas lhes aprouveram: ou destruir a cidade, ou então dividir tudo em dois, todo o patrimônio que continha a cidade aprazível. (Ilíada, XVIII, v. 490 a 512, tradução de Frederico Lourenço)

É possível discernir, nessa passagem da Ilíada latina, um retorno à Era de Ouro, característica da política a favor de Nero. Quando o jovem imperador chegou ao poder foi aclamado como bom governante e o povo se alegrava com as realizações iniciais do imperador, depois dos abusos de Cláudio. Esse mesmo tema da era de Ouro também pode ser encontrado na Apocolocintose de Sêneca, que denuncia a crueldade do imperador Cláudio, e as virtudes de Nero, seu sucessor, que inclusive tinha sua figura ligada a Apolo, como patrono das artes, da paz e da justiça (SCAFFAI, 1997, p. 20).

Podemos também ver, na passagem abaixo da Ilíada latina, outros elementos que ajudam a datar a obra. Durante o episódio do livro XIX, no qual Netuno salva Eneias da morte, Bébio assim escreve:

Se o senhor das grandes águas ${ }^{7}$ não o tivesse protegido, para que exilado restabelecesse Troia em férteis terras e pusesse a augusta estirpe sob brilhantes astros, não teria persistido até nós a origem de célebre descendência ${ }^{8}$. (Ilíada latina, XIX, v. 899 a 902, tradução nossa)

\footnotetext{
7 Posêidon, em latim Netuno, deus dos mares.

$8 \mathrm{O}$ mito romano atribui a Eneias a origem de seu povo. Após escapar da guerra de Troia, ele se estabelece na Itália e se torna antecessor dos gêmeos Rômulo e Remo, míticos fundadores da cidade de Roma. Augusto, primeiro imperador romano e sobrinho de Júlio César, atribuía a origem de sua família ao filho de Eneias, Ascânio. Daí a menção à descendência de Eneias nesses versos.

Organon, Porto Alegre, v. 29, n. 56, p. 297-312, jan/jun. 2014.
} 
Podemos ver que o poeta faz referência à estirpe de Augusto, primeiro imperador romano, pois sua família (a gens Julia) se dizia descendente direta de Eneias. Percebe-se ainda o encômio à família imperial e sua descendência, família esta cujo último membro governante foi Nero. Vimos que no início de seu governo ele foi muito celebrado como imperador bom e justo, e posteriormente tornou-se violento e sanguinário. Com ele se encerrou a dinastia Júlio-Cláudia, pois Nero suicidou-se em 68 , sem ter designado seu sucessor.

\section{A estrutura da Ilíada latina}

A Ilíada latina nos chegou dividida em 24 livros, assim como a obra homérica, divisão esta que foi provavelmente feita pelos copistas da Antiguidade, ou também pode remontar ao uso do texto nas escolas (para facilitar a consulta), e não pelo próprio autor. Isso se justifica porque a divisão dos livros não é muito clara e, em alguns casos, parece dar-se dentro do mesmo verso. A divisão dos livros nem sempre respeita a divisão homérica, pois Bébio modifica a sucessão de alguns eventos, sobretudo na parte final, onde a narrativa é bem resumida.

A Ilíada latina resume a Ilíada de Homero de maneira bastante irregular. Os cinco primeiros livros correspondem à metade da obra, enquanto os outros 19 livros se condensam na outra metade. Isso poderia indicar que o autor não teve interesse, ou ânimo, de fazer um resumo proporcional. Alguns episódios são retratados de maneira bem detalhada, enquanto outros são completamente excluídos.

A extrema condensação de alguns livros os torna simples passagens de transição. Os livros mais resumidos da Ilíada latina são o XIII e o XVII, sendo este último reduzido a apenas três versos. Às vezes o autor também funde vários episódios em apenas um e, por consequência, atribui a uma mesma personagem ações que em Homero são desempenhadas por personagens distintas.

Os versos iniciais são praticamente iguais a Homero, o que denota que Bébio os sabia de cor. De fato, não poderia ser possível a Bébio adaptar a obra grega sem manter o conhecidíssimo proêmio; o primeiro verso vale como título da obra e é fundamental para conectar a adaptação ao modelo original. Têm-se ainda graves confusões com nomes e personagens secundários, que poderiam ter sido causadas pelo próprio poeta ou pela tradição manuscrita.

Ao contrário de um epítome, no qual há um resumo metódico e regular de cada livro, a obra de Bébio resume a Ilíada de forma seletiva. A narrativa se desenrola com o uso de fórmulas e símiles semelhantes à obra homérica, buscando imitar o aspecto formal do poema grego.

Organon, Porto Alegre, v. 29, n. 56, p. 297-312, jan/jun. 2014. 


\section{Comparações entre a Ilíada latina e a Ilíada}

A Ilíada narra momentos específicos da longa guerra de Troia, que durou dez anos, ao centrar a narrativa em Aquiles, o maior dos heróis gregos. Uma característica marcante da Ilíada é sua narrativa não linear: ora as personagens preveem os acontecimentos (por exemplo, o cavalo de Aquiles, Xanto, prevê a morte de seu dono, no canto XIX, vv. 408 a 410), ora a própria narrativa se adianta ao momento dos acontecimentos narrados.

A estrutura narrativa é realizada através de vários episódios que possuem certa interdependência entre si. O enredo ora se acelera, ora é monótono e descritivo, e alterna momentos intensos de descrição de batalhas com momentos pacíficos.

As divindades, independentemente do lado que defendem, interferem intensamente nos acontecimentos da guerra. Os deuses ora podem ser o mote da ação, como por exemplo, no canto III, em que Atena faz com que Pândaro dispare sua flecha contra Menelau e termine com o acordo entre troianos e gregos; ora podem agir conjuntamente com os homens, como no canto XV (262 a 270), em que Apolo incita Heitor, insuflando-lhe força e coragem.

É possível perceber que, através dos episódios que Bébio escolhe omitir ou narrar em detalhes, temos certa unidade no enredo da Ilíada Latina. Abordamos apenas algumas comparações quanto ao enredo da Ilíada latina em relação a Homero.

Os episódios que menos interessam a Bébio são os que retratam as assembleias - tanto de homens quanto de deuses - com seus longos discursos e diálogos. Bébio Itálico resume muito essas longas falas, e muitos diálogos ocorrem em poucos versos, retratados na maioria das vezes de maneira indireta. Podemos destacar como exemplo, o início do canto IV. No poema homérico, este canto principia com um concílio entre os deuses, no qual Zeus discute com Hera e Atena sobre a guerra de Troia, até que, por fim, Zeus manda Atena suscitar a luta entre troianos e gregos (v. 1 a 103). A Ilíada latina resume essa passagem nos seguintes versos (344 a 349):

E enquanto os líderes disputavam entre si, o onipotente governante do Olimpo convocou um concílio9, e Pândaro violou o pacto ${ }^{10}$ com o arco retesado

9 Itálico omite o assunto do concílio, no qual os deuses discutem sobre a guerra de Troia. $10 \mathrm{O}$ pacto feito, descrito no livro anterior, previa apenas a luta de Páris contra Menelau. Na Ilíada, é a deusa Atena que incita Pândaro a atirar a flecha. Na Ilíada Latina, a ação de Pândaro não possui influência divina.

Organon, Porto Alegre, v. 29, n. 56, p. 297-312, jan/jun. 2014. 
atingindo-te, Menelau, a voadora flecha entra nas costas e corta a túnica enrijecida com escamas de ferro. O Atrida, gemendo, sai da batalha. (Ilíada latina, IV, v. 344 a 349, tradução nossa)

Consequentemente, a Ilíada latina perdeu o tom solene, heroico e aristocrático da epopeia grega. Os generais do exército se aproximam mais, portanto, do modelo do exército romano. Se na Ilíada todos os troianos que suplicam clemência aos gregos são mortos, na Ilíada latina Menelau age como romano, quando faz um prisioneiro para ornar seu triunfo:

(...) Menelau captura o enorme Adrasto e o arrasta até as esquadras, com as mãos amarradas às costas, a fim de que, por sua força, consiga do inimigo felizes triunfos. (Ilíada latina, VI, v. 539 a 541, tradução nossa)

Os instrumentos bélicos na adaptação latina têm nomes romanos, como a formação em tartaruga:

Os frígios invadem a entrada e no primeiro limiar derrubam os gregos restantes, expulsando os batalhões da trincheira; outros pedem escadas para as muralhas e lançam chamas: a vitória aumenta as forças.

Dos muros e por torres altas os dânaos lutam.

Pedras voam, os troianos aproximam-se, feita a tartaruga ${ }^{11}$, sobem pelo acesso e nas portas com forças ameaçam.

(Ilíada latina, XII, v. 762 a 768, tradução nossa)

Além de combaterem com carro, os personagens da Ilíada latina também lutam a cavalo. Na Ilíada, em contrapartida, não existem cavaleiros. Destacamos dois trechos da adaptação latina:

Aqui um, lançado pelo carro veloz nas planícies, é pisoteado e ao mesmo tempo esmagado pelas patas dos cavalos; outro, atravessado o corpo pelo dardo voador, cai rápido do dorso do quadrúpede; a cabeça daquele,

11 Esta é uma referência à formação de tartaruga, na qual os soldados fazem uma espécie de proteção, colocando os escudos acima da cabeça. Técnica do exército romano, é um dos anacronismos que Itálico coloca em seu resumo. O mesmo se pode dizer também da formação do acampamento grego, descrita nesse livro. 
cortada pela espada, correu para longe do pescoço;

(Ilíada latina, V, v. 476 a 480, tradução nossa)

Quando viu os aliados cederem ao hostil Marte,

o sublime rei dos dânaos ${ }^{12}$ corre a cavalo em volta das tropas,

encoraja os chefes e fortalece os ânimos para as lutas.

(Ilíada latina, V, v. 495 a 497, tradução nossa)

Além disso, no canto X da Ilíada latina, Ulisses e Diomedes prestam contas a Agamêmnon como dois disciplinados soldados que se reportam ao seu superior:

(...) Depois que estavam em seus acampamentos, os fatos ao chefe relatam: o herói Pelopeu elogia, e os seus fatigados membros entregam ao agradável repouso.

(Ilíada latina, X, v. 738 a 740, tradução nossa)

Em Homero, por outro lado, nos versos finais do canto X, no momento em que Diomedes e Ulisses retornam, eles são recebidos por Nestor. Agamêmnon sequer é mencionado nesse episódio.

Por fim, o acampamento grego sempre é descrito na Ilíada latina à maneira dos acampamentos romanos, com fosso e trincheira. No ataque dos troianos, os gregos:

Agitados pelo medo, saltam pelas valas e pelos muros cercados de terra, outros são derrubados no próprio fosso.

(Ilíada latina, XV, v. 792 e 793, tradução nossa)

Bébio Itálico também elimina quase que por completo a intervenção dos deuses nas batalhas e as interpolações aos heróis. Por isso, muitas das ações que na Ilíada são provocadas ou influenciadas por um deus, no poema latino se devem unicamente à ação humana, como vimos no episódio de Pândaro, destacado acima.

Bébio Itálico também chega a suprimir episódios completos que possuem participações dos deuses. Nessa categoria podemos incluir, por exemplo, o canto XIV da Ilíada. Na obra homérica, esse canto é conhecido desde a Antiguidade como o Dolo de Zeus, devido ao famoso episódio em que Hera seduz Zeus e o faz dormir, dando chance para que o deus Posêi-

$12 \mathrm{O}$ rei dos dânaos é, naturalmente, Agamêmnon, que anima seus homens.

Organon, Porto Alegre, v. 29, n. 56, p. 297-312, jan/jun. 2014. 
don intervenha a favor dos gregos. Podemos destacar o encontro de Zeus e Hera a partir dos seguintes versos da Ilíada:

(...) e nos seus braços tomou a esposa o filho de Crono. Debaixo deles a terra divina fez crescer relva fresca, a flor de lótus orvalhada e açafrão e jacintos macios em profusão, que os mantiveram acima do solo.

Foi nesse leito que se deitaram, ocultando-se numa nuvem bela e dourada, a qual destilava gotas reluzentes.

Deste modo, adormeceu tranquilo o Pai no píncaro de Gárgaro, subjugado pelo sono e pelo amor, com a esposa nos braços.

Porém o Sono suave correu até às naus dos Aqueus para dar a notícia ao deus que segura e sacode a terra.

Postando-se junto dele proferiu palavras apetrechadas de asas:

"com afinco agora aos Dânaos, ó Posídon, presta auxílio! Outorga-lhes a glória, exígua embora seja sua duração, enquanto dorme Zeus, já que o cobri com o sono macio: pois Hera o seduziu para com ele se deitar em amor." (Ilíada, XIV, v. 346 a 360, tradução de Frederico Lourenço)

Já na Ilíada latina, temos um resumo bastante radical do livro XIV de Homero. Bébio retira todo o episódio do Dolo de Zeus, resumindo em apenas 11 versos os 135 versos finais deste canto da Ilíada, e dá maior destaque às lutas entre gregos e troianos:

E quando o feroz Heitor no violento peito se enfurece, o enorme Ájax o afastou, ao atingi-lo com uma grande pedra, e o derrubou, prostrando-o de corpo inteiro.

Aproxima-se a troiana tropa e lavaram o jovem, que vomitava rios de sangue, nas águas do Xanto ${ }^{13}$.

De lá de novo à luta retornam; faz-se enorme matança

de ambos e a terra emana, suja de sangue.

Polidamante com forte golpe mata Protenor; Ájax Telamônio, o Antenórida Arquéloco ${ }^{14}$; Acamante, o beócio Prômaco, mas derruba-o a destra do atroz Peneleu; depois cai a priameia juventude ${ }^{15}$. (Ilíada latina, XIV, v. 779 a 789, tradução nossa)

13 Rio que existia perto de Troia.

14 Arquéloco, filho de Antenor.

15 Juventude de Príamo, ou seja, troiana. 
Também é possível encontrar certa unidade narrativa nos episódios que são mantidos. Nesta categoria, interessam a Bébio os episódios de caráter sentimental, como o amor paternal. Podemos destacar, no canto I da Ilíada latina, a emocionada súplica de Crises por sua filha. Assim Crises se dirige a Apolo:

"De que me adianta, Délfico, eu ter honrado tuas vontades, ou ter levado uma vida casta por muitos anos? Ou de que adianta ter posto os sacros fogos nos altares, se agora eu, teu sacerdote, sou humilhado pelo inimigo estrangeiro?

Acaso estes são os dons ofertados à abandonada velhice? Se sou caro a ti, que eu esteja seguro sob tua vingança. Ou se, ignorante, cometi alguma falta para que fosse castigado diante de um grave crime, ó, por que pára a tua destra?

Toma os arcos sagrados, e volta contra mim as tuas flechas: certamente o causador da morte será um deus. Eis! Traspassa o culpado pai. Por que a filha expia os erros do pai e, miserável, suporta o leito do cruel inimigo?"

(Ilíada latina, I, v. 32 a 43, tradução nossa)

Já o tom da súplica de Crises a Apolo, na Ilíada de Homero, possui outra conotação. Crises não menciona o amor pela filha, e sim a desonra que os gregos o fizeram passar. Assim diz o sacerdote:

"Ouve-me, senhor do arco de prata, deus tutelar de Crise e da sacratíssima Cila, que pela força reges Ténedo, ó Esminteu! Se alguma vez o belo templo te pus um tecto, ou queimei para ti as gordas coxas de touros ou de cabras, faz que se cumpra isto que te peço: que paguem com tuas setas os Dânaos as minhas lágrimas!" (Ilíada, I, v. 37 a 42, tradução de Frederico Lourenço)

A súplica de Príamo a Aquiles pelo cadáver de Heitor, no canto XXIV, também se inclui na patética cena de demonstração de amor paternal, como podemos ver nesse trecho da Ilíada latina:

(...) "Ó fortíssimo Aquiles do povo grego,

ó inimigo dos meus reinos, a ti somente a vencida

Organon, Porto Alegre, v. 29, n. 56, p. 297-312, jan/jun. 2014. 
juventude dardânia teme, e nossa velhice sentiu a ti

cruel demais. Agora peço que sejas afabilíssimo

e tenhas compaixão do pai aflito, que suplica de joelhos,

e aceites os presentes, que trago pelo corpo do miserável filho, se nem com pedidos nem com ouro te dobras, que a tua destra se enfureça nos derradeiros anos de um velho: ao menos, pai, eu me juntarei aos cruéis funerais do filho. Nem a vida ou grandes honras me concedas, mas meu cruel funeral! Apieda-te de um pai e aprenda por minha pessoa a ser um pai afável. Com a morte de Heitor, venceste os dardânios reinos, venceste Príamo; vencedor, recorda-te da sorte humana e observa os vários destinos dos heróis." (Ilíada latina, XXIV, v. 1028 a 1042, tradução nossa)

Na Ilíada, contudo, temos a seguinte fala de Príamo a Aquiles, que denota um tom mais solene, e a referência à morte de Heitor que, além de filho, era o principal defensor de Troia:

"Pensa no teu pai, ó Aquiles, semelhante aos deuses! Ele que tem a minha idade, na soleira da dolorosa velhice. Decerto os que vivem à volta dele o tratam mal, e não há ninguém que dele afaste o vexame e a humilhação. Porém quando ouve dizer que tu estás vivo, alegra-se no coração e todos os dias sente esperança de ver o filho amado, regressado de Tróia. Mas eu sou totalmente amaldiçoado, que gerei filhos excelentes na ampla Tróia, mas afirmo que deles não me resta nenhum. Eram cinquenta, quando chegaram os filhos dos Aqueus. Dezenove nasceram do mesmo ventre materno; os outros foram dados à luz por mulheres no palácio. A estes, numerosos embora fossem, Ares furioso deslassou os joelhos. E o único que me restava, ele que sozinho defendia a cidade e o povo, esse tu mataste quando ele lutava para defender a pátria:

Heitor. Por causa dele venho às naus dos Aqueus para te suplicar; e trago incontáveis riquezas. Respeita os deuses, ó Aquiles, e tem pena de mim, lembrando-te do teu pai. Eu sou mais desgraçado que ele, e aguentei o que nenhum outro terrestre mortal aguentou, pois levei à boca a mão do homem que me matou o filho". (Ilíada, XXIV, v. 486 a 506, tradução de Frederico Lourenço) 
Entre essas duas passagens, Scaffai ressalta que "o centro da súplica é este, o resgate em troca do corpo de Heitor, como nos versos 501 a 506 da Ilíada, ainda que o ethos desta parte do epítome tenha sido estabelecido mais sobre o patético, despojadas as palavras de Príamo daquele halo de dignidade que elas mantêm na Ilíada." ${ }^{16}$

Em Homero, é Tétis que leva a Aquiles a ordem de Zeus para devolver o corpo de Heitor a Príamo, mediante o pagamento de generoso resgate. Ela assim diz a seu filho:

Ora ouve-me agora, pois para ti sou mensageira de Zeus.

Diz que os deuses estão irados contra ti; e ele mais do que todos está grandemente enfurecido, porque tu com espírito tresloucado reténs o corpo de Heitor nas naus recurvas e não o restituis. Mas agora restitui o morto e aceita o resgate pelo cadáver. (Ilíada, XXIV, v. 133 a 137, tradução de Frederico Lourenço)

Aquiles segue o conselho de sua mãe, aceita o pagamento de Príamo e devolve o corpo de Heitor. No resumo latino não temos, no canto XXIV, a influência dos deuses no resgate do corpo de Heitor. $\mathrm{Na}$ adaptação latina, a ideia de buscar Heitor parte de um gesto de coragem de Príamo. Ao contrário da obra grega, na adaptação, Aquiles, comovido com a súplica de Príamo, devolve o cadáver de Heitor. Essa mudança na narrativa reforça em Aquiles um caráter mais piedoso do que ele possui na Ilíada. Vejamos os versos destacados a seguir:

Por fim, movido por esses pedidos, Aquiles levanta o velho da terra e o corpo exangue de Heitor devolve ao pai. Depois disso, Príamo leva seus presentes para a pátria; as tristes exéquias, à maneira dos seus, prepara, e conduz os derradeiros funerais. (Ilíada latina, XXIV, 1043 a 1047, tradução nossa)

Traduzimos, no verso 1045 o trecho sua dona por "seus presentes", pois Itálico se refere ao corpo de Heitor resgatado por Príamo.

Outra diferenciação que Bébio Itálico realiza na narrativa é a paixão amorosa com funestas consequências entre as personagens. Podemos per-

16 "Il centro della preghiera è questo, il riscatto in cambio del corpo di Ettore (in Hom. 501 ss.), anche se l'ethos di questa parte dell'epitome è impostato più sul patetico, spogliate le parole di Priamo di quell'alone di dignità che mantengono nell'Iliade." (SCAFFAI, 1997, p. 423 e 424)

Organon, Porto Alegre, v. 29, n. 56, p. 297-312, jan/jun. 2014. 
ceber isso na disputa de Aquiles contra Agamêmnon por Briseida, no canto I. A Ilíada latina retrata a discussão entre Agamêmnon e Aquiles, porém vemos que essa atitude de Agamêmnon foi motivada por amor passional. Além disso, é possível notar como a participação de Atena na cena foi reduzida ao mínimo possível:

(...) Depois, censura o grande Aquiles e, por sua vez, ele atura os insultos do herói invencível. Todos bramiram juntos. Por fim, cessado o barulho, é forçado, triste, a renunciar aos forçados amores e devolve Criseida intacta ao piedoso pai, além de muitos presentes. Ulisses, conhecido por todos, transportou-a, colocada sobre a popa, até as cidadelas pátrias, e novamente virou suas velas para as esquadras dos dânaos. Imediatamente as vontades do hostil Febo são aplacadas e são devolvidas aos aquivos ${ }^{17}$ as forças quase esgotadas. Contudo, a paixão do Atrida por Criseida não cessou: lamenta-se e, desiludido, chora os perdidos amores. Sem demora, despoja Aquiles da raptada Briseida ${ }^{18}$ e alivia suas chamas com as chamas alheias. Porém o feroz Eácida, ${ }^{19}$ desnudando logo a espada, avança contra o Atrida e, se não lhe restituísse os prêmios da honrada campanha, ameaça-o de morte cruel; não menos aquele, com a espada, prepara-se em resposta para a defesa.

Pois se a casta Palas $^{20}$ não tivesse segurado Aquiles com a mão, o cego amor teria deixado para sempre torpe fama $\operatorname{argólicos}^{21}$. (...)

(Ilíada latina, I, v. 60 a 80, tradução nossa)

Em Homero, temos a fala de Aquiles, na qual ele mostra para Agamêmnon sua indignação com a atitude de arrebatar o prêmio de algum dos heróis gregos:

Fitando-o com sobrolho carregado, respondeu Aquiles de pés velozes:

$17 \mathrm{O}$ mesmo que gregos.

18 Briseida fora dada a Aquiles como prêmio de guerra.

19 Aquiles, filho de Peleu e neto de Éaco.

20 Palas Atena, deusa da sabedoria.

21 Referente à cidade grega de Argos, na região da Argólida, aqui serve como sinônimo de "grego". 
"Ah, como te vestes de vergonha, zeloso do teu proveito! Como obedecerá às tuas palavras algum dos Aqueus, para seguir caminho ou pelejar pela força contra guerreiros? Eu não vim para aqui lutar por causa dos lanceiros Troianos, visto que eles em nada me ofenderam: nunca eles me levaram bois ou cavalos, nem jamais na Ftia de férteis sulcos, alimentadora de homens, prejudicaram as colheitas, pois muitas coisas há de permeio: montanhas sombrias e o mar retumbante.

Mas foi a ti, grande desavergonhado!, que seguimos, para que te regozijasses, para que obtivéssemos honra para Menelau:

foi por ti, ó cara de cão!, que investimos contra os Troianos. Mas nisto não queres tu pensar nem reflectir.

E ameaças vir tu próprio tirar-me o prêmio, pelo qual muito me esforcei, e que me deram os filhos dos Aqueus. Nunca recebo eu prémios como os teus, quando saqueiam os Aqueus uma das cidades bem habitadas dos Troianos. A maior porção da guerra impetuosa têm as minhas mãos de aguentar; mas quando chega o momento da distribuição, és tu que ficas com o prémio melhor; e eu volto para as naus com coisa pouca, mas que me é querida, depois de me ter cansado a combater. Mas agora voltarei para a Ftia, visto que é muito melhor regressar a casa com as naus recurvas, pois não estou disposto a ficar aqui, desonrado, acumulando para ti tesouros.”

(Ilíada, I, v. 148 a 171, tradução de Frederico Lourenço)

Temos, no trecho acima, não a motivação amorosa que aparece na Ilíada latina, mas sim o desrespeito ao butim de guerra que é devido a cada herói. Quando Agamêmnon resolve tomar Briseida de Aquiles, ele o desonra enquanto guerreiro. Episódios tópicos da poesia épica - como o catálogo das naus do canto II, na qual são elencados os povos que participaram do exército grego e do exército troiano - foram mantidos de maneira próxima, apesar de Bébio Itálico excluir o catálogo dos cavalos levados pelos gregos. Esse catálogo foi preservado, embora possua certa aridez narrativa, justamente por ser uma parte da Ilíada muito conhecida e imitada.

$\mathrm{Na}$ realidade Bébio foi apenas um modesto representante da poesia épica de cunho classicista, e reelabora Homero sem visar a mais do que

Organon, Porto Alegre, v. 29, n. 56, p. 297-312, jan/jun. 2014. 
seus modelos canônicos. Sua única intenção é produzir um exercício de tradução poética do grego, sem deixar-se envolver em um resumo de perspectiva total da Ilíada (SCAFFAI, 1997, p. 27).

A redução da Ilíada para apenas 1070 versos inevitavelmente acarreta perda da profundidade original, mas a Ilíada latina também encerra aspectos interessantes. É possível ver claramente como o autor entendia a Ilíada, através das passagens e aspectos (mitológicos, estilísticos etc.) que ele escolhe transmitir, além de suas omissões e inovações em relação ao texto original.

\section{BIBLIOGRAFIA}

ALMEIDA, Zélia Cardoso. A literatura latina. São Paulo: Martins Fontes, 2003. BUTLER, H. E. Post-Augustan Poetry. Charleston: Biblio Bazaar, 2008. CONTE, Gian Biagio. Latin Literature: a history. Trad. Joseph B. Solodow. Baltimore: Johns Hopkins University Press, 1999.

HOMERO. Ilíada. Trad. Frederico Lourenço. Lisboa: Cotovia, 2005. KENNEY, E. J.; CLAUSEN, W.V. (eds.). Historia de la literatura clásica. (Cambridge University) Madrid: Gredos, 1989 v. 2 Literatura latina. KIRK, G. S. (ed.) The Iliad: a commentary. Cambridge: Cambridge University Press, 1995, 6v.

LESKY, Albin. História da literatura grega. Lisboa: Fundação Calouste Gulbenkian, 1995.

MARTIAL. Epigrams. Cambridge: Harvard University Press, 1947. The Loeb Classical Library, vol.1.

PARRY, Adam (ed.). The making of homeric verse. New York: Arno Press, 1980. PEREIRA, Maria Helena da Rocha. Estudos de historia da cultura classica. 7. ed. Lisboa: Fundação C. Gulbenkian, 1993, 2 v.

SCAFFAI, Marco (ed). Baebii Italici Ilias Latina: Introduzione, edizione critica, traduzione italiana, e commento. Bologna: Pàtron, 1997.

VEGA, María Felisa del Barrio. LÓPEZ, Vicente Cristóbal (eds). La Ilíada Latina; Diario de la guerra de Troya de Dictis Cretense; Historia de la destrucción de Troya de Dares Frigio. Madrid: Gredos, 2001.

Recebido em: 10/12/2013. Aceito em: 21/03/2014. 